\title{
On-Chip Micromachined Dielectric Resonator Antennas Loaded with Parasitic Circular/Crescent Patch for mm-Wave Applications
}

\author{
Mai Sallam ${ }^{1,2}$, Mohamed Serry ${ }^{1}$, Sherif Sedky ${ }^{1,3}$, Atif Shamim ${ }^{4}$, Guy A. E. Vandenbosch ${ }^{5}$, and Ezzeldin A. Soliman ${ }^{1, *}$ \\ ${ }^{1}$ The American University in Cairo, AUC Avenue, P. O. Box 74, New Cairo11835, Egypt, esoliman@aucegypt.edu \\ ${ }^{2}$ Ahram Canadian University, $4^{\text {th }}$ Industrial zone, $6^{\text {th }}$ October, Giza \\ ${ }^{3}$ Zewail City for Science and Technology, $6^{\text {th }}$ October, Giza \\ ${ }^{4}$ King Abdullah University of Science and Technology (KAUST), Thuwal, Saudi Arabia \\ ${ }^{5}$ ESAT/TELEMIC, KU Leuven, 3001 Leuven, Belgium
}

\begin{abstract}
In this paper, two designs of micromachined dielectric resonator antennas operating at $60 \mathrm{GHz}$ are presented. The antennas are fabricated using a single silicon wafer in which the dielectric resonator is located at one side of the wafer while the feeding network is located on the other side. The feeding lines are terminated by magnetic dipole which excite the dielectric resonator and causes its radiation. In order to enhance the bandwidth of the antenna, the dielectric resonator is loaded with circular/crescent patch antenna. Both designs are characterized by their fabrication simplicity, and high radiation performance. Additionally, the proposed antennas have wide impedance bandwidth reaching more than $10 \%(21 \%)$ of the central frequency for the circular/crescent patch loaded dielectric resonator antennas.
\end{abstract}

Index Terms - Dielectric resonator antennas (DRAs), micromachining technology, patch antenna, crescent antenna, on-chip antennas.

\section{INTRODUCTION}

There is an ever increasing demand for high-gain antennas especially at $60 \mathrm{GHz}$. Hybrid antennas are considered one of the possible solutions to enhance the gain. In the literature, Dielectric Resonator Antennas (DRAs) with upper patch have been presented using different methods. One of these methods is using the patch antenna to excite the DRA [1-4]. The DRA is constructed from a material of high dielectric constant with inner slot of rectangular, circular or elliptical shape. The patch antenna is mounted on top of a low permittivity substrate and is located inside this slot. To achieve high gain, the DRA is excited with a high order mode which necessitates a large electric size for the DRA. Another combination for the DRA and patch antennas has been presented in [5]. In this design, the patch antenna is elevated in air using a number of posts. The DRA is located on top of this patch. Another antenna structure has been suggested in [6]. For this design, the patch antenna is located on top of the DRA which is fed using a coaxial cable. The different size of the patch and the DRA results in a dualband.

In this paper, DRAs loaded with two types of patch antennas are presented. First, we considered the DRA loaded with circular patch. Then we proposed to use a crescent patch above the DR since they are capable of providing wide impedance bandwidth [7-9]. As far as the authors know, this design has not been proposed previously in the literature. The proposed antennas combine various advantages including high directivity, high radiation efficiency, and wide bandwidth. Additionally the antennas are characterized by their fabrication simplicity, where only a single wafer is required for their fabrication. The new antennas have better radiation characteristics and wider bandwidth compared to the unloaded DRA presented in [10].

\section{ANTENNA TOPOLOGY AND OPERATION}

\section{A. Dielectric Resonator Loaded with Circular Patch}

Fig. 1 shows the topology of the first proposed DRA. It consists of a dielectric resonator (DR) made of a highresistivity silicon $(2000 \Omega . \mathrm{cm})$, and a circular patch made of copper which is placed on top of the circular DR. The patch has slightly smaller radius compared to the DR. The antenna is fed via a coplanar waveguide $(\mathrm{CPW})$ transmission line placed at the backside of the wafer which is terminated by a magnetic dipole. Unlike the DRA presented in [10], the location of the magnetic dipole is exactly at the center of the DRA. The antenna has been carefully optimized so that the desired characteristics are obtained. The optimum antenna parameters are listed in Table I. The DR has a height $H=$ $400 \mathrm{~nm}$, while the substrate thickness $T=275 \mu \mathrm{m}$. The dimensions of the CPW transmission lines are chosen such they are matched to $50 \Omega$.

The antenna operates when the CPW is excited with the odd mode. Afterwards, magnetic currents flow along the magnetic dipole resulting in the excitation of the DR. The patch placed on top of the DRA is also excited and radiates. Since the radius of the DR and that of the patch are slightly different, each of them has a different resonance location. By adjusting both radii, we are able to obtain overlapping resonances leading to an increased overall impedance bandwidth, as will be presented in the next section.

\section{B. Dielectric Resonator Loaded with Crescent Patch}

The second proposed antenna recognizes a crescent patch antenna over the DR, as shown in Fig. 2. This antenna is created by etching a circular aperture inside the patch on top of the DRA. Another circular patch of smaller radius is 


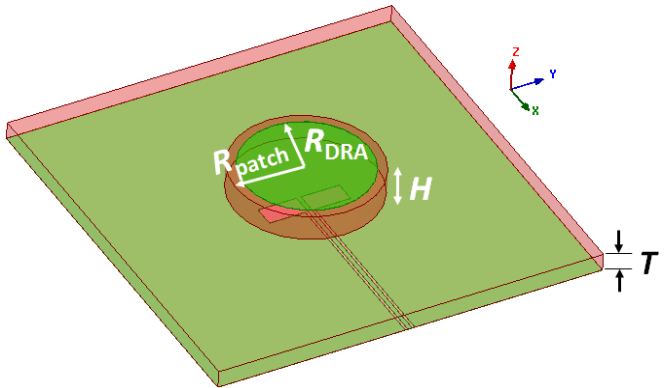

(a)

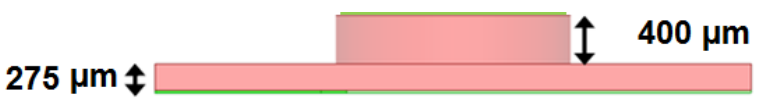

(b)

Fig.1. Topology of the proposed DRA loaded with circular patch, (a) 3D-view, and (b) side view.

TABLE I

OPTIMUM DIMENSIONS OF THE DRA LOADED WITH CIRCULAR PATCH

\begin{tabular}{cccc}
\hline \hline Antenna & OPTIMUM & Antenna & Optimum Value \\
Parameter & VALUE & Parameter & \\
\hline$L$ & $1.27 \mathrm{~mm}$ & $W$ & $0.32 \mathrm{~mm}$ \\
$R_{D R A}$ & $1.1 \mathrm{~mm}$ & $R_{\text {patch }}$ & $0.97 \mathrm{~mm}$
\end{tabular}

TABLE II

OPTIMUM DimenSIONS OF THE DRA LOADED WITH CRESCENT PATCH

\begin{tabular}{cccc}
\hline \hline $\begin{array}{c}\text { Antenna } \\
\text { Parameter }\end{array}$ & OPTIMUM & Antenna & Optimum Value \\
VAlameter & Parame & $W$ & $0.12 \mathrm{~mm}$ \\
$D$ & $1.618 \mathrm{~mm}$ & $S$ & $0.08 \mathrm{~mm}$ \\
$R_{l}$ & $0.57 \mathrm{~mm}$ & $R_{2}$ & $1.13 \mathrm{~mm}$ \\
$R_{D R A}$ & $0.45 \mathrm{~mm}$ & &
\end{tabular}

placed inside this circular aperture. The radii of the circular aperture and the inner patch are denoted by $R_{1}$ and $R_{2}$ respectively. The centers of the aperture and the inner patch are shifted such that an overall crescent aperture is formed. The antenna parameters are optimized to achieve wide bandwidth and high directivity. The optimum parameters are listed in Table II.

Similar to the DRA loaded with circular patch, the operation of the DRA loaded with crescent patch is achieved when the feeding lines are excited with their odd mode. In such case, the DRA is excited via the magnetic dipole located underneath it. For this antenna, the magnetic dipole is shifted away from the center of the DRA, as shown in Fig. 2. The excitation of the DRA leads to the excitation of the crescent antenna where an electric field is created inside the crescent-shape aperture. Fig. 3 shows the electric field distribution along the top side of the DRA. As shown, the main field is created along the $x$-axis, which matches that of the DRA. As a result, both radiation due to the DRA and the crescent add constructively leading to a directive radiation pattern. On the other hand, the fields along the $y$-axis cancel out and do not contribute to the antenna radiation.

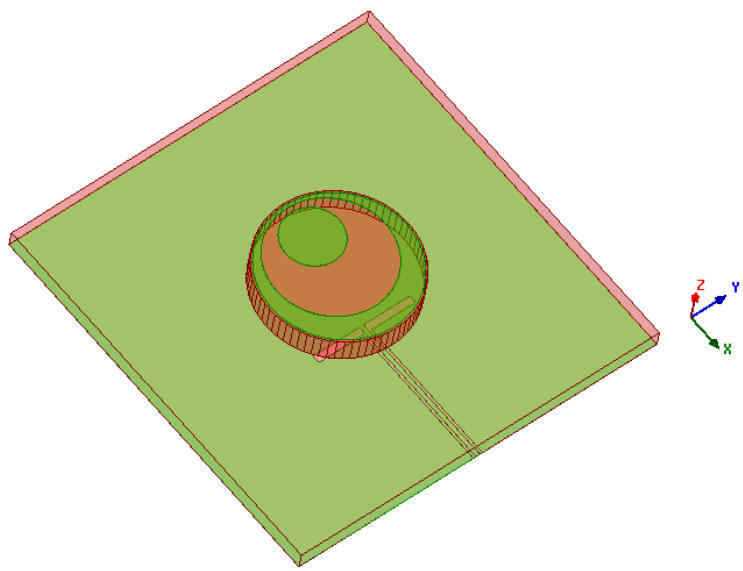

(a)

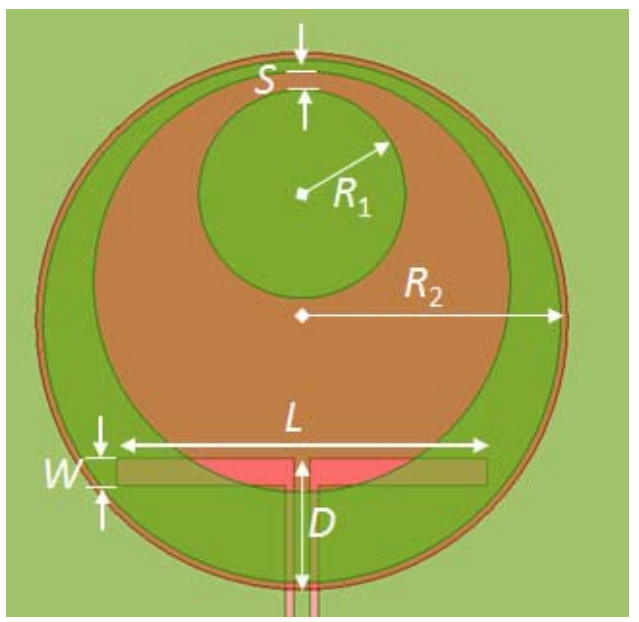

(b)

Fig. 2. Topology of the proposed DRA loaded with crescent patch (a) $3 \mathrm{D}$ view, and (b) top-view

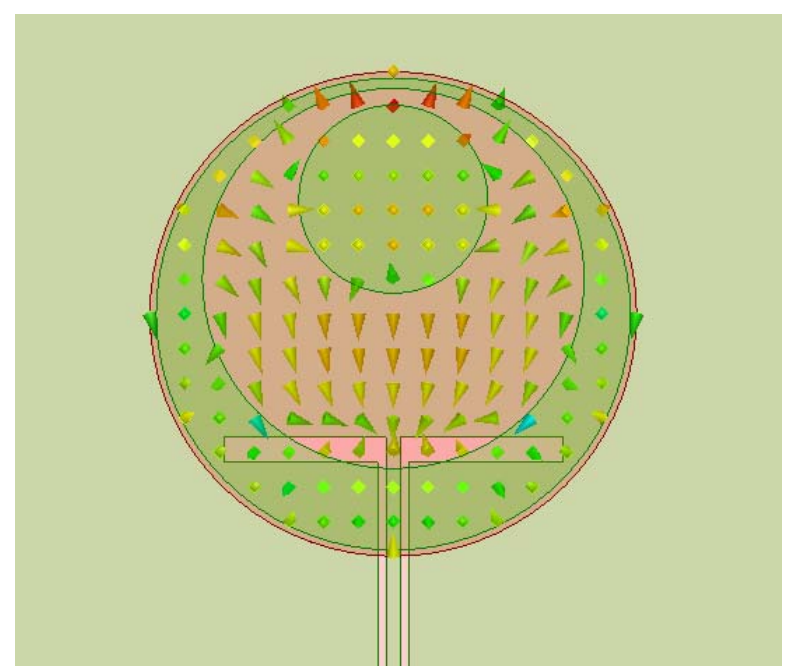

Fig. 3 Electric field distribution along the top side of the DRA loaded with crescent patch at $60 \mathrm{GHz}$. 


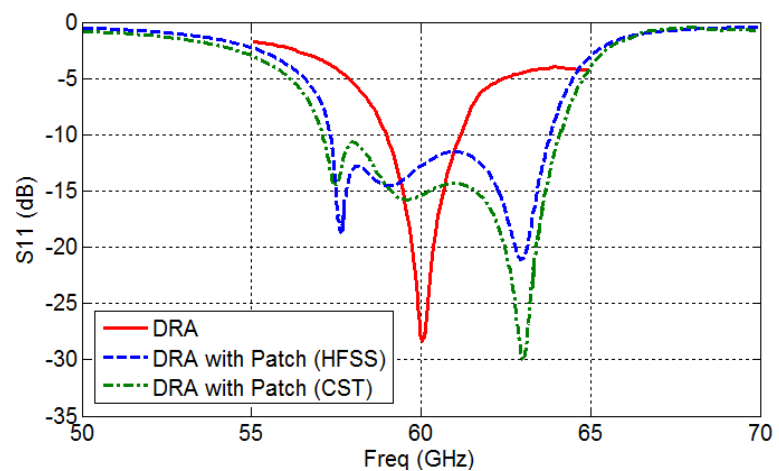

Fig. 4. Reflection coefficienct versus frequency for the DRA with/without circular patch

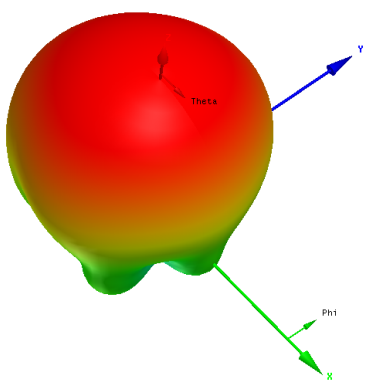

(a)

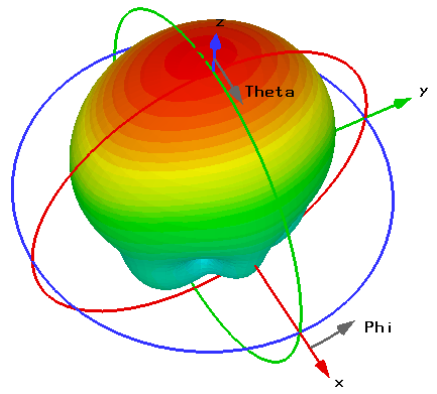

(b)
Fig. 5. 3D radiation pattern of the DRA loaded with circular patch at $60 \mathrm{GHz}$ as simulated using (a) HFSS, and (b) CST.

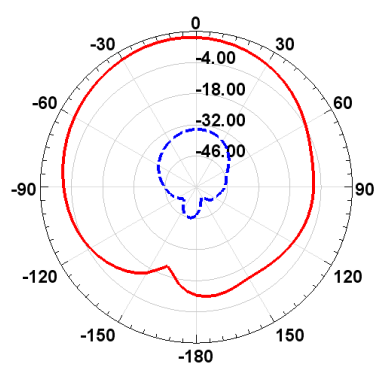

(a)

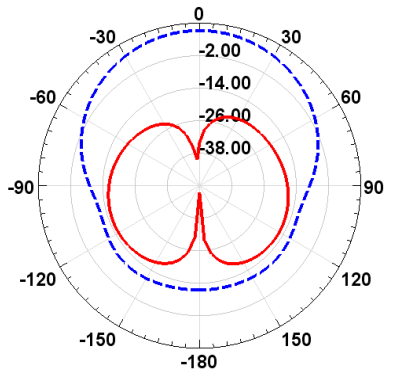

(b)
Fig. 6. 2D radiation pattern of the DRA loaded with circular patch at $60 \mathrm{GHz}$ (a) $E$-plane, and (b) $H$-plane (red line: GainTheta, blue dashed line: GainPhi).

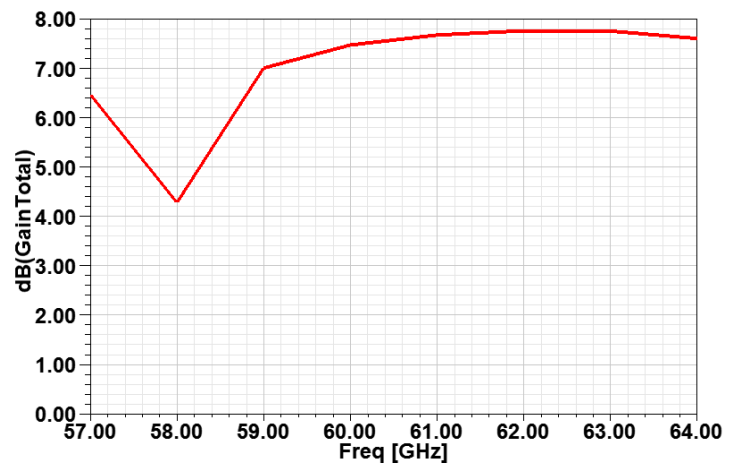

Fig. 7. Bore-sight gain of the DRA loaded with circular patch versus frequency.

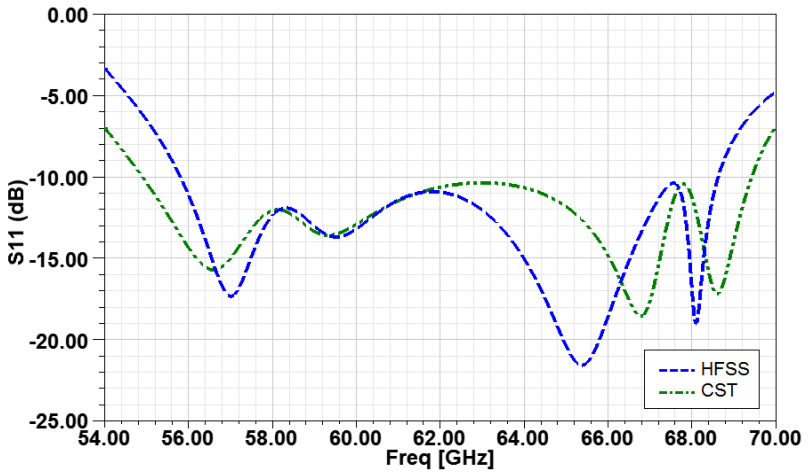

Fig. 8. Reflection coefficienct versus frequency for the DRA loaded with crescent patch as simulated using HFSS and CST.

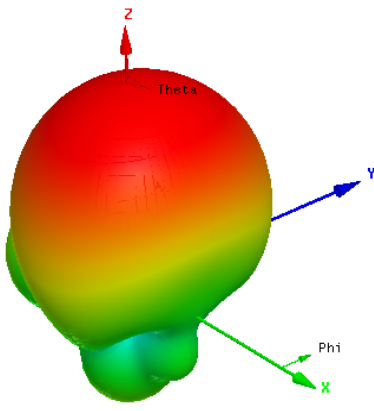

(a)

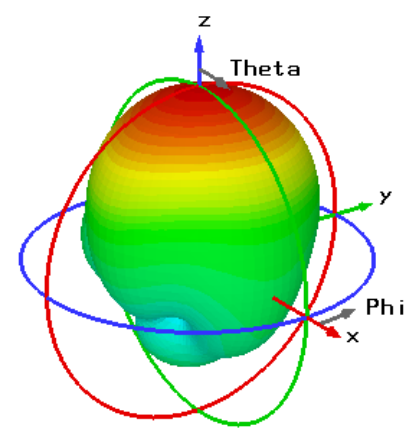

(b)
Fig. 9. 3D radiation pattern of the DRA loaded with crescent patch at 60 GHz as simulated using (a) HFSS, and (b) CST.

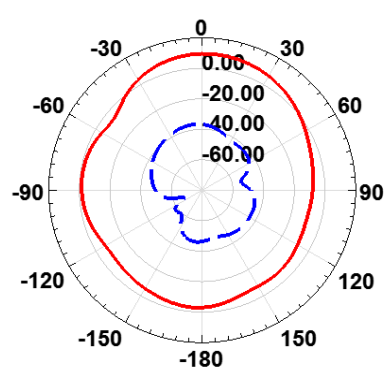

(a)

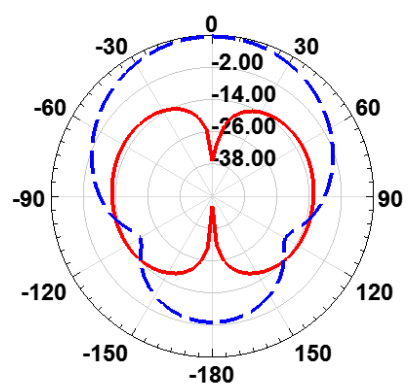

(b)
Fig. 10. 2D radiation pattern of the DRA loaded with crescent at $60 \mathrm{GHz}$ (a) $E$-plane, and (b) $H$-plane (red line: GainTheta, blue dashed line: GainPhi).

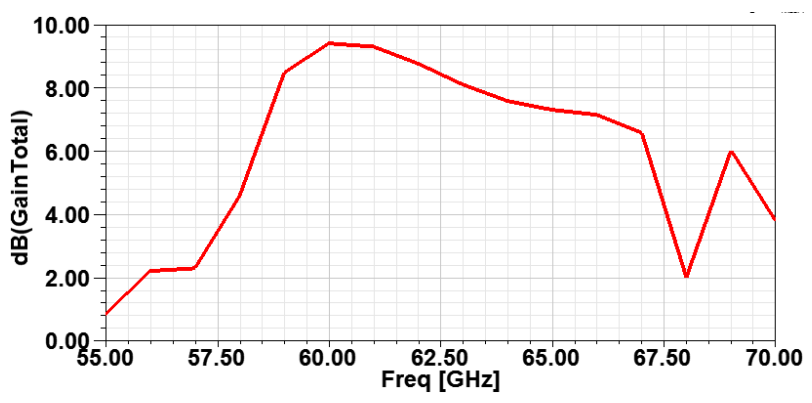

Fig. 11. Bore-sight gain of the DRA loaded with crescent versus frequency. 


\section{FABRICATION}

The major advantage of the proposed antennas is their fabrication simplicity, where only five fabrication steps are required. It is worth noting that the proposed antennas are fabricated using six-inch $675 \mu \mathrm{m}$ thick double sided polished high-resistivity silicon wafers $\left(\rho_{\mathrm{si}} \geq 2,000 \Omega . \mathrm{cm}\right)$. To obtain the cylindrical DR, Deep Reactive Ion Etching process is required to remove the silicon around the DRA while maintaining vertical cylindrical sidewall. The backside of the silicon wafer acts as the substrate which carries the antennas feeding network. To pattern the antenna's feeding network, the backside of the substrate is first coated with copper film with thickness greater than 5 $\mu \mathrm{m}$ using an electroplating process. Dry etching is then used to define the feeding network of the antenna. Another metallization and patterning steps are required in order to define the circular/crescent patch located above the DR.

\section{SimUlations AND DiscUSSION}

\section{A. Dielectric Resonator Loaded with Circular Patch}

This section shows the characteristics of the proposed DRAs. In order to verify the results, two simulators HFSS and CST have been used and compared. Fig. 4 shows the reflection coefficient versus frequency for the DRA loaded with circular patch compared with the simple DRA presented in [10]. As seen, the addition of the patch leads to increasing the bandwidth from $2.23 \mathrm{GHz}(3.71 \%)$ to $6.48 \mathrm{GHz}(10.8 \%)$. It is also noticed that both HFSS and CST are in a very good agreement where the latter results in a slightly larger bandwidth. The new DRA has three resonance frequencies resulting from the magnetic dipole, the DR, and the patch antenna. These resonances overlap with each other leading to a wide impedance bandwidth. The radiation pattern of the DRA at $60 \mathrm{GHz}$ is shown in Fig. 5. Due to the presence of the ground plane, the antenna radiates only at the bore-sight with very low radiation at the backside. The $2 \mathrm{D}$ radiation patterns of the antenna are shown in Fig. 6. The antenna has a low cross-polarization level along the two principal planes which is due to the perfect symmetry. Summarized results are shown in Table III. Both HFSS and CST simulators agree very well. In comparison with [10], it is noticed that not only does this design increases the antenna's impedance bandwidth, but it also enhances its directivity since there are two radiators instead of one. To examine the radiation characteristics over the working bandwidth of the antenna, Fig. 7 shows the bore-sight gain of the antenna versus frequency. It is clear that the antenna has a reasonable gain all over the working bandwidth with a minimum value of 4.3 $\mathrm{dB}$ at $58 \mathrm{GHz}$.

\section{B. Dielectric Resonator Loaded with Crescent Patch}

For the DRA loaded with crescent patch, Fig. 8 shows the reflection coefficient versus frequency. Results obtained from HFSS and CST are generally in good agreement. CST shows wider impedance bandwidth compared to HFSS. It is evident that the new design enhanced the bandwidth of the
TABLE III

CHARACTERISTICS OF THE DRA LOADED WITH UPPER PATCH

\begin{tabular}{|l|c|c|}
\hline \multicolumn{1}{|c|}{$\begin{array}{c}\text { Antenna } \\
\text { Characteristics }\end{array}$} & HFSS & $C S T$ \\
\hline $\begin{array}{l}\text { Impedance Bandwidth } \\
(-10 \mathrm{~dB})\end{array}$ & $\begin{array}{c}6.48 \mathrm{GHz} \\
(10.8 \%)\end{array}$ & $\begin{array}{l}6.98 \mathrm{GHz} \\
(11.63 \%)\end{array}$ \\
\hline Directivity & $7.90 \mathrm{dBi}$ & $9.20 \mathrm{dBi}$ \\
\hline Radiation Efficiency & $99.47 \%$ & $94.41 \%$ \\
\hline Gain & $7.83 \mathrm{dBi}$ & $8.95 \mathrm{dBi}$ \\
\hline $\begin{array}{l}\text { Cross-Polarization Level } \\
\text { @ Broadside }\end{array}$ & $-41.30 \mathrm{~dB}$ & $-57.20 \mathrm{~dB}$ \\
\hline $\begin{array}{l}\text { Maximum Cross- } \\
\text { polarization Level }\left(\phi=0^{\circ}\right. \\
\text { plane) }\end{array}$ & $-41.30 \mathrm{~dB}$ & $-57.00 \mathrm{~dB}$ \\
\hline $\begin{array}{l}\text { Maximum Cross- } \\
\text { Polarization Level }\left(\phi=90^{\circ}\right. \\
\text { plane) }\end{array}$ & $-23.55 \mathrm{~dB}$ & $-23.36 \mathrm{~dB}$ \\
\hline Front-to-Back Ratio & $18.73 \mathrm{~dB}$ & $20.49 \mathrm{~dB}$ \\
\hline
\end{tabular}

TABLE IV

CHARACTERISTICS OF THE DRA LOADED WITH CRESCENT ANTENNA

\begin{tabular}{|c|c|c|}
\hline $\begin{array}{c}\text { Antenna } \\
\text { Characteristics }\end{array}$ & HFSS & CST \\
\hline $\begin{array}{c}\text { Impedance Bandwidth } \\
(-10 \mathrm{~dB})\end{array}$ & $\begin{array}{c}12.78 \mathrm{GHz} \\
(21.3 \%)\end{array}$ & $\begin{array}{c}14.46 \mathrm{GHz} \\
(24.1 \%)\end{array}$ \\
\hline Directivity & $9.59 \mathrm{dBi}$ & $8.34 \mathrm{dBi}$ \\
\hline Radiation Efficiency & $97.46 \%$ & $92.59 \%$ \\
\hline Gain & K29.44 dBi & $7.76 \mathrm{dBi}$ \\
\hline $\begin{array}{c}\text { Cross-Polarization Level } @ \\
\text { Broadside }\end{array}$ & $-46.28 \mathrm{~dB}$ & $-56.41 \mathrm{~dB}$ \\
\hline $\begin{array}{c}\text { Maximum Cross-polarization } \\
\text { Level } \\
\left(\phi=0^{\circ} \text { plane }\right)\end{array}$ & $-46.28 \mathrm{~dB}$ & $-48.26 \mathrm{~dB}$ \\
\hline $\begin{array}{c}\text { Level } \\
\left(\phi=90^{\circ} \text { plane }\right)\end{array}$ & $-21.30 \mathrm{~dB}$ & $-19.89 \mathrm{~dB}$ \\
\hline Front-to-Back Ratio & $12.52 \mathrm{~dB}$ & $11.87 \mathrm{~dB}$ \\
\hline
\end{tabular}

antenna almost twice that of the DRA loaded with circular patch. The $3 \mathrm{D}$, and $2 \mathrm{D}$ radiation patterns of the antenna shown in Figs. 9 and 10 demonstrate the high radiation characteristics of the new proposed antenna. At $60 \mathrm{GHz}$, the antenna achieved a directivity of $9.59 \mathrm{dBi}$, which is higher than that obtained using a DRA loaded with circular patch. The new antenna also has high polarization purity where a maximum cross polarization level along the $E$ - and $H$-planes is $-23.55 \mathrm{~dB}$. The high radiation performance of this antenna is also achieved over a wideband, as shown from Fig. 11, where the antenna's gain is above $6 \mathrm{~dB}$ in the frequency range from $58.5 \mathrm{GHz}$ to $67 \mathrm{GHz}$. Table IV presents a summary for the characteristics of this antenna. It is obvious that the DR loaded with crescent achieved the best radiation characteristics and the widest impedance bandwidth compared to the unloaded DRA and the DRA loaded with circular patch.

\section{CONCLUSION}

The paper presented two designs of DRAs intended for mm-wave applications. The first (second) design realizes a circular (crescent) patch antenna located at the top side of the 
DRA. The proposed designs are very simple and can be fabricated using micromachining technology in few steps. The addition of the circular or the crescent patch above the DRA leads to a wider impedance bandwidth and a more directive radiation pattern. The DRA loaded with crescent patch demonstrated the best performance compared to the DRA and the DRA loaded with circular patch. The next step is to fabricate and characterize these antennas to verify the results obtained from simulations.

\section{REFERENCES}

[1] A. Perron, T. A. Denidni, and A. R. Sebak, "High-Gain Circularly Polarized Millimeter-Wave Antenna," Antennas and Propagation Society International Symposium, June 2009.

[2] A. Perron, T. A. Denidni, and A. R. Sebak, "High-Gain Hybrid Dielectric Resonator Antenna for Millimeter-Wave Applications: Design and Implementation," IEEE Transactions on Antennas and Propagation, vol. 57, no. 10, October 2009.

[3] A. Elboushi, O. M. Haraz, A. Sebak, and T. Denidni, "A New Circularly Polarized High Gain DRA Millimeter-Wave Antenna," Antennas and Propagation Society International Symposium, September 2010.

[4] A. Perron, T. A. Denidni, and A. R. Sebak, "Circularly Polarized Microstrip/Elliptical Dielectric Ring Resonator Antenna for Millimeter-Wave Applications," IEEE Antennas and Wireless Propagation Letters, vol. 9, 2010.

[5] J. Oh, T. Baek, D. Shin, J. Rhee, and S. Nam, “60-GHz CPW-fed Dielectric Resonator-Above-Patch (DRAP) Antenna For Broadband WLAN Applications using Micromachining Technology," Microwave and Optical Technology Letters, vol. 49, no. 8, August 2007.

[6] H. Wu, X. Wu, C. Hua, and N. Yang, "A Dual Frequency Rectangular Dielectric Resonator Antenna Fed by a Coaxial Probe," Progress In Electromagnetics Research Symposium Proceedings, Suzhou, China, Sept. 2011.

[7] M. O. Sallam, S. M.. Kandil, V. Volski, G. A. E Vandenbosch, E. A. Soliman, "2.4/5 GHz WLAN crescent antenna on flexible substrate," $10^{\text {th }}$ European Conference on Antennas and Propagation (EuCAP), Davos, Switzerland, April 2016.

[8] E.A. Soliman, S. Brebels, E. Beyne, and G. A. E. Vandenbosch, "Dual frequency wide band cusp antenna fed by coplanar waveguide," 28th European Microwave Conference (EuMC), Amsterdam, The Netherlands, Oct. 1998, vol. 2, pp. 7-11.

[9] A. Gautam and S. Verma, "Printed Crescent-Shaped Monopole Antenna with Defected Ground Structure for Wireless Applications," 2018 3rd International Conference for Convergence in Technology (I2CT), Pune, pp. 1-5, 2018.

[10] M. O. Sallam, M. Serry, S. Sedky, A. Shamim, W. De Raedt, G. A. E. Vandenbosch, and E. A. Soliman, "Micromachined On-Chip Dielectric Resonator Antenna Operating at $60 \mathrm{GHz}$," IEEE Trans. Antennas and Propag., vol.63, no.8, August 2015. 